\title{
Thriving Under Uncertainty: The Effect of Achievement Goal Orientation on Job Insecurity and Flourishing
}

\author{
Arjan van Dam ${ }^{1} \cdot$ Gera Noordzij $^{2} \cdot$ Marise Born ${ }^{2,3}$
}

Accepted: 15 April 2020 / Published online: 4 May 2020

(c) The Author(s) 2020

\begin{abstract}
Flourishing, a construct encompassing optimal human functioning, is an indicator of well-being. The purpose of this study was to examine the direct and indirect effects of employees' achievement goal orientation (mastery-approach, mastery-avoidance, performance-approach and performance-avoidance goal orientation) on flourishing, through the appraisal of quantitative (concerns about continued existence of the job) and qualitative (concerns about continued existence of important job features) job insecurity. Data were collected from 275 employees in an organization on the brink of a substantive downsizing. The results of structural equation modelling showed that mastery approach and-avoidance goal orientation positively predicted flourishing. Furthermore, flourishing was negatively predicted by qualitative job insecurity but not by quantitative job insecurity. Qualitative job insecurity mediated the effects of mastery- and performance-approach goal orientation on flourishing but the effects were not significant. Hence, in an environment with a substantial threat of job loss, a mastery goal orientation contributed directly to flourishing. Our results plead for more attention for the effects of achievement goal orientation and qualitative job insecurity on flourishing under uncertainty.
\end{abstract}

Keywords Achievement goal orientation - Qualitative job insecurity · Quantitative job insecurity $\cdot$ Flourishing

Arjan van Dam

info@fidare.nl

Gera Noordzij

noordzij@euc.eur.nl

Marise Born

born@fsw.eur.nl

1 Fidare, Heijermanslaan 27, 1215 JL Hilversum, The Netherlands

2 Erasmus University Rotterdam, P.O. Box 1738, 3000 DR Rotterdam, The Netherlands

3 Optentia and Faculty of Economic and Management Sciences, North-West University South Africa, Vanderbijlpark, South Africa 


\section{Introduction}

Job insecurity is not only associated with negative well-being, but also seems to be a cause of it and as such is viewed as a threat to well-being (e.g., De Witte et al. 2016). During their working life almost all employees are, at a certain moment, confronted with the specific adversity of uncertainty of the future of their job and job insecurity seems to have become reality for a vast number of employees (Organisation for Economic Co-operation and Development 1997). The results of a survey among European employees showed that $17 \%$ of them experienced job insecurity (Eurofound 2016). Job insecurity is considered to be one of the prominent psychosocial risk factors at work (Leka and Jain 2010) and not surprisingly, a considerable amount of cross-sectional as well as longitudinal research has been dedicated to the effects of job insecurity (e.g., Cheng and Chan 2008; De Witte 2010; Sverke and Hellgren 2002).

Job insecurity refers to "the anticipation of this stressful event (i.e., actual job loss) in such a way that the nature and continued existence of one's job are ' to be at risk." (Sverke and Hellgren 2002, p. 27). In addition to the uncertainty about the continuity of their job (quantitative job insecurity), employees are also facing changes in their work that can lead to uncertainty about the quality (e.g., stimulating job content or pay development) of their job (qualitative job insecurity) (Hellgren et al. 1999).

Research has consistently demonstrated that job insecurity is negatively related to wellbeing and that it therefore is detrimental for both organizations and individuals (e.g., De Witte 2010; Griep et al. 2016). So far, research on the effects of job insecurity on wellbeing typically focused on (life) satisfaction and positive and negative affect (in other words, hedonic well-being). However, some researchers called for a broader look at wellbeing (e.g. Ryan and Deci 2001) by incorporating eudaimonic well-being as an important aspect of well-being. Eudaimonic well-being refers to actualizing one's human potential reflected in optimal psychological and social functioning, ranging from supportive relationships to purpose and meaning in life (Deci and Ryan 2008; Keyes 2007). Eudaimonic well-being is relevant in relation to the effects of job insecurity on well-being, because eudaimonic well-being makes it possible to examine further-reaching effects of job insecurity on well-being. The importance of a high eudaimonic well-being has also been demonstrated by a study that showed that the highest mental health was found among people with both high hedonic and eudaimonic well-being (Keyes 2002). In addition, having a high hedonic well-being (i.e., being positively affective and satisfied) does not necessarily mean that someone has a high eudaimonic well-being. Thus, by examining the effects of job insecurity on eudaimonic well-being (labeled from here as flourishing), profound effects on well-being might be revealed that remain hidden if only hedonic well-being is considered.

Perceived job insecurity is typically characterized as a stressor in which the appraisal of a potential threat plays a central role (Sverke et al. 2002). In turn, personal goals and beliefs (e.g., self-efficacy) are important determinants of one's appraisal processes, which in turn mediates the relation between stressors and well-being (Lazarus and Folkman 1987). In relation to job insecurity, the type of goal one sets might influence whether the potential loss of one's job (i.e. quantitative job insecurity) or valued job features (i.e., qualitative job insecurity), is appraised as a threat. According to the achievement goal orientation theory by Dweck and Leggett (1988), people can have different personal goal preferences in achievement situations (e.g., work) (Payne et al. 2007). Individuals' achievement goals are relevant for the appraisal process of stressors, for the reason that they create the framework within which individuals 
interpret and react to events (Dweck and Leggett 1988). At the same time, one's personal goals will influence one's flourishing, with some type of goals leading to more flourishing than others (Deci and Ryan 2000; Emmons 2003). In sum, the kind of personal goals someone wants to achieve could not only directly influence flourishing but might, by means of one's appraisal of the insecurity of one's job, result in differences in flourishing.

The present study therefore aims to contribute to the literature by: (1) investigating the direct effects of both quantitative and qualitative job insecurity as well as achievement goals on flourishing, (2) looking at the indirect effect of achievement goals on flourishing through job insecurity (quantitative and qualitative) and (3) offering opportunities to positively influence well-being in times of job uncertainty.

\section{Job Insecurity and Flourishing}

Job insecurity refers to "employed people who feel threatened by unemployment" (De Witte 2005, p. 1), and as such it is a subjective rather than an objective phenomenon (Greenhalgh and Rosenblatt 1984). This implies that there might be differences between individuals in their appraisal of job insecurity even if they are exposed to the same circumstances. Job insecurity is mostly viewed as an unidimensional construct; the threat of losing one's job. However, Hellgren et al. (1999) argued that this unidimensional construct does not take into account the threat to someone's career options and employment conditions that might likely happen in times of reorganization and downsizing of organisations. They, therefore, summoned to make a distinction between quantitative and qualitative job insecurity. Quantitative job insecurity concerns the continued existence of one's job, and qualitative job insecurity concerns the continued existence of important job features. Both quantitative and qualitative insecurity are seen as job stressors. For instance, when one's job is not directly threatened, one's career opportunities can be substantially restricted by an organizational change.

The relationship of job insecurity with flourishing (eudomianic well-being) has been researched only scarcely (see for an exception, Rautenbach and Rothmann 2017; Rothmann 2013). Given the lack of clear empirical evidence we will base our expectations on previous findings of the relationship between job insecurity and well-being (i.e., hedonic well-being), which has shown that perceived job insecurity reduces wellbeing of employees (De Witte 2010, Griep et al. 2016). Although the effects of job insecurity on hedonic well-being and flourishing may differ these outcomes are highly correlated $(r=.79 ; p<.01)$ (Fredrickson et al. 2013). The study by Hellgren et al. (1999) found that qualitative job insecurity was clearly related to employee well-being, cross sectionally as well as longitudinally, whereas quantitative job insecurity only (negatively) predicted job satisfaction. There is also evidence that well-being outside the work domain (e.g., at home) is negatively affected by both quantitative and qualitative job insecurity (e.g. Hellgren et al. 1999; Lim and Sng 2006; Westman et al. 2001). Furthermore, Vander Elst et al. (2014a) reported that qualitative job insecurity was also related to depressive symptoms, such as sad feelings, a low self-worth, and a lack of interest in life. Based on the previous findings that job insecurity has a detrimental effect on hedonic well-being, a negative relation between job insecurity (qualitative and quantitative) and flourishing (eudaimonic well-being) is likely. 


\section{Achievement Goal Orientation, Job Insecurity and Flourishing}

This study examines to what extent goal orientation has a direct and indirect effect, through job insecurity, on well-being (i.e., flourishing). Thus, we expect that goal orientation is directly related to both flourishing and job insecurity, and that it also indirectly is related to flourishing. First, we will elaborate on the achievement goal theory, after which the expected relation between goal orientation and flourishing (i.e., well-being) will be described and finally, the supposed effect of goal orientation on job insecurity.

According to the achievement goal orientation (AGO) theory (Dweck and Leggett 1988) individuals differ in their preference for certain goals in achievement situations. Dweck and Leggett's AGO theory originally distinguished between a preference for mastery goals and a preference for performance goals, stating that mastery goals were more adaptive than performance goals. Their argument for this idea is that mastery goals focus on a task directly, and thus will contribute to learning (Dweck and Leggett 1988). Later, Elliot ad McGregor (2001) added a distinction between avoidance and approach goals to both mastery and performance goals, and argued that approach goals are more adaptive than avoidance goals because approach goals will help a person to reach positive outcomes (see also Elliot et al. 2011). The addition of the approach-avoidance distinction resulted in the following $2 \times 2$ achievement goal orientation framework: (1) a mastery-approach (Map), implying a focus on improvement of one's competence and gaining mastery over a task, (2) a mastery-avoidance approach (Mav), in which the focus is on avoiding incompetency and preventing to lose mastery over a task, (3) a performance-approach (Pap), where the focus is on showing one's competence and gaining positive judgments from others, and (4) a performance-avoidance (Pav) approach, which focuses on avoiding to show incompetence and preventing unfavorable judgments from others.

In general, one's goals in life and at work have been shown to be indirectly related to one's well-being (e.g., by means of cognitive appraisals) but also directly (cf. Emmons 2003). More specifically, an approach goal orientation (i.e. striving for a desired outcome) has been demonstrated to contribute to one's well-being, whereas an avoidance goal orientation (i.e. avoiding an undesired outcome) has a detrimental effect (Elliot et al. 1997). Furthermore, mastery goals are positively related to well-being (Dykman 1998), while performance goals are negatively related to well-being (Kaplan and Maehr 1999; Tuominen-Soini et al. 2008). Based on these findings we expect a positive relation between Map goals and flourishing and a negative relation of flourishing with Pav goals. For Mav goals, a positive effect of mastery goal orientation is expected to be counteracted by a negative impact of the avoidance goal orientation. For Pap goals the positive impact of an approach goal orientation will potentially be counteracted by a negative impact of a performance goal orientation. Therefore, no relation between flourishing and both Pap and Mav goals are to be expected.

The (potential) threat of losing one's job is typically viewed as a stressor, and therefore the expected relation between job insecurity and one's goal orientation can be explained by looking at the cognitive appraisal of such a stressor. A fundamental attribute of an appraisal is that there is an assessment of a (potential) loss or gain (Lazarus and Folkman 1987). Already before the concept of the appraisal of stress was advanced, Lazarus et al. (1952) had concluded that one's goals play a central role in stress: "We would then think that stress occurs when a particular situation threatens the attainment of some goal." (p. 295). Therefore, the role of personal goals in the appraisal of threat is crucial. 
In a similar vein, a recent literature review on goal orientations concludes that goal orientations are related to cognitive appraisals; a Map goal orientation is negatively related to threat appraisals, a performance-avoidance goal orientation is positively related to threat appraisals and the relation with performance-approach goal orientation proves often non-significant (Vandewalle et al. 2019). Moreover, adopting Map goals is associated with appraising an achievement situation not only as less of a threat, but also as more of a challenge (Elliot and Reis 2003). For example, employees with a higher Map goal orientation might feel less threatened by the potential loss of their job (compared to colleagues with a low Map goal orientation), because they see this more of as a challenge. In contrast, employees with a high Pav goal orientation might feel threatened by the potential loss of their job, because they fear the possible negative judgements of others when they would lose their job. Furthermore, adopting Map goals is positively associated with self-directed career management (Briscoe et al. 2006), feeling employable and feeling that one's job is secure (Lin 2015). In this way, we expect that employees with a high Map goal orientation will experience less job insecurity and those with a higher Pav goal orientation experience more job insecurity. However, Vandewalle et al. (2019) have unfortunately not included Mav goal orientation in their review, but earlier studies (Adie et al. 2008, 2010) among participants in a competitive sports setting have shown that Mav goals were positively related to threat appraisals. Thus, earlier research seems to suggest that employees with a higher Mav goal orientation will experience higher levels of job insecurity. However, recently the detrimental effects of Mav goals on performance and well-being have been nuanced by Senko and Freund (2015). Their study showed that Mav goals were more adaptive for older than for younger people; the negative effects on motivation and performance were more likely for the young than for the elderly. When Mav goals are more adaptive for older people, it can be assumed that these goals will also be less strongly related to threat appraisals among them. Our sample of working adults consists of older employees, and therefore we expect that the relation with threat appraisals will be absent. Thus, a relationship between both Mav and Pap goal orientation and job insecurity is not expected in our sample, but as it is too premature to exclude possible effects of both Mav and Pap goals on job insecurity, all AGO's will be included in our study.

\section{Hypothesized Model}

The present study examines the effects of AGO on flourishing and proposes that this effect is mediated by the appraisal of quantitative and qualitative job insecurity. Based on theory and previous research (e.g., Elliot and McGregor 2001; Huang 2011), we build a model in which Map (positively) and Pav (negatively) are related to quantitative and qualitative job insecurity and flourishing, and flourishing is negatively related to quantitative and qualitative job insecurity (see Fig. 1). For clarity, in the hypothesized model Mav and Pap goal orientation are incorporated, but no effects are hypothesized. It should be noted that mediation implies longitudinal causality, which cannot be demonstrated with cross-sectional data (MacKinnon et al. 2007). Therefore, our aim is to conduct a preliminary test of the hypothesized model. 
Fig. 1 Theoretical model: relations between achievement goal orientation, quantitative and qualitative job insecurity and flourishing. Note: Map = Mastery-approach, Mav = Mastery-avoidance, Pap $=$ Performance-approach, Pav $=$ Performance-avoidance. The hypotheses are displayed by their abbreviations

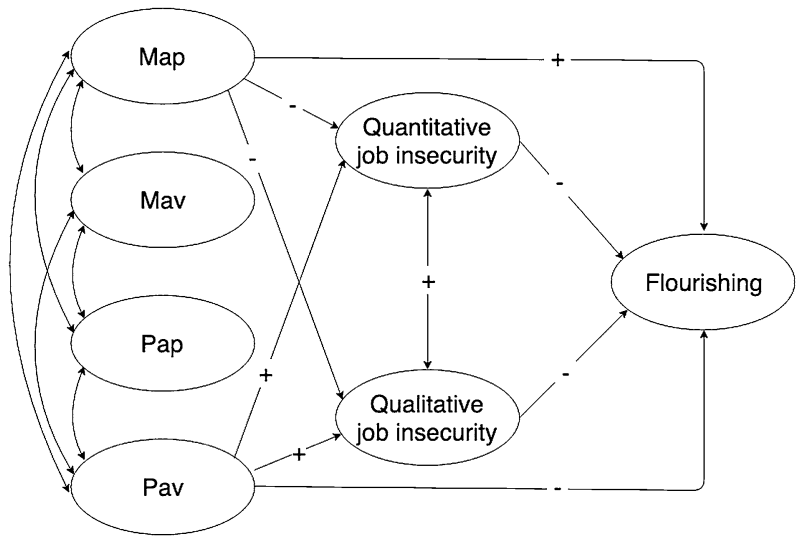

\section{Method}

\subsection{Respondents and Procedure}

All employees $(N=487)$ of an organization in the Netherlands that provides Youth Care (e.g., foster care and guiding complicated family problems), were given the opportunity receive career advice, from an independent organization, as part of a reorganization. The reorganization started in the first half of 2014 and ended in the middle of 2015, resulting in the exit of 145 employees (30\%). To get a career advice, they had to complete a questionnaire. The results were presented in a report that a career professional discussed with each employee in an individual interview. All employees were invited by email to fill out an online questionnaire in Dutch from July 2014 to November 2014, wherein the confidentiality of their results, report and interview was warranted. All participants were native Dutch and proficient in the Dutch language. By filling out the questionnaire they approved with the confidentiality in handling their results. The results of the questionnaire did not affect in any way their chance to get fired. After 10 weeks the employees who had not filled out the questionnaire received a reminder.

In total, $56.5 \%$ of the employees completed the questionnaire, resulting in a final sample of 275 employees ( 224 female, 51 male). The relative low percentage of male workers $(22.8 \%)$ is comparable to the percentage of men in similar organisations in Youth Care (23\% in 2014) (AZW 2017). The mean age was 43.5 years $(S D=10.81)$, the mean weekly working hours was $29.01(S D=6.47)$ and the average years of work experience was 20.50 $(S D=10.62)$. Regarding the highest educational level, .7\% had finished primary education; $4.7 \%$ lower general secondary education; $14.2 \%$ higher general secondary education, and $80.4 \%$ had finished higher vocational training.

\subsection{Measures}

\subsubsection{Achievement Goal Orientation}

The scales to measure the four achievement goal orientations were based on the scales by VandeWalle (1997) and Baranik et al. (2013). Map was measured with 4 items, an example item is: "I enjoy challenging and difficult tasks at work where I'll learn new skills" 
$(\alpha=.85)$; Pap (4 items), example item: "I enjoy it when others at work are aware of how well I am doing" ( $\alpha .=76)$; Pav (4 items), example item: "Avoiding a show of low ability is more important to me than learning a new skill" ( $\alpha=.73)$; and Mav goal orientation (4 items), example item: "I just hope I am able to maintain enough skills so I am competent at my job" $(\alpha=.77)$. All items are scored on a 5-point Likert scale, ranging from $1=$ strongly disagree to $5=$ strongly agree.

\subsubsection{Flourishing}

Flourishing was measured with the 8-item Flourishing Scale developed by Diener et al. (2010). Example items are: "I actively contribute to the happiness and well-being of others", "I lead a purposeful and meaningful life", and "I am engaged and interested in my daily activities" ( $\alpha=.87)$. Items are scored on a 7-point scale, ranging from $1=$ strongly disagree to $7=$ strongly agree.

\subsubsection{Quantitative Job Insecurity}

A 5-item scale was used to measure quantitative job insecurity (Handaja and De Witte 2007). An example item is: "I'm afraid to be fired" ( $\alpha=.82)$. Items are scored on a 5-point scale, ranging from $1=$ strongly disagree to $5=$ strongly agree. A high score indicated high job insecurity.

\subsubsection{Qualitative Job Insecurity}

A 4-item scale was used to measure qualitative job insecurity (Hellgren et al. 1999). An example item is: "My future career opportunities in the organization are favourable". Items are scored on a 5 -point scale, ranging from $1=$ strongly disagree to $5=$ strongly agree $(\alpha=.79)$. Items were reverse scored so that a high score indicated high job insecurity. A confirmatory analysis (CFA; see for details below)showed that one item ("I believe that [the organization] will need my competence also in the future") had to be removed due to a low factor loading. The reliability of the scale with the remaining items was $\alpha=.81$.

\subsubsection{Control Variables}

To control for potential effects of socio-demographic characteristics the following variables were measured: respondents' gender $(0=$ male, $1=$ female), age (in years), highest educational level $(1=$ primary education, $2=$ lower general secondary education, $3=$ higher general secondary education, and $4=$ higher vocational training), and weekly working hours. The aforementioned variables are known to be related to quantitative job insecurity and well-being (e.g., Argyle 1999; Cheng and Chan 2008; Näswall and De Witte 2003). We performed a hierarchical regression analysis in which flourishing was regressed on job insecurity, AGO and the control variables. The control variables were not significantly related to flourishing. Therefore, the control variables were excluded from further analyses.

\subsection{Statistical Analyses}

Structural Equation Modelling (SEM) was applied, with Mplus (2017) and the R package MplusAutomation (Hallquist and Wiley 2018; R Core Team 2012), to test the hypotheses 
with the use of the Maximum Likelihood Estimation (ML). ML makes the distributional assumption that variables have a multivariate normal distribution. Absolute values of the skew index which are higher than 3 , and for the kurtosis index higher than 10 , are regarded as violations of this assumption (Kline 2011). The observed variables met those requirements.

The following fit indexes were used to assess the fit of the models: Tucker-Lewis index (TLI), Comparative Fit Index (CFI), Standardized Root Mean Square Residual (SRMR) and Root Mean Square Error of Approximation (RMSEA) (Hoyle 2012; Kline 2011). Fit indices above a value of .95 for the ML-based indices (TLI, CFI), a value lower than .08 for SRMR, and a value lower than .06 for RMSEA are recommended (Hu and Bentler 1999). A Chi square difference test was performed to compare the alternative nested models. We performed a two-step approach wherein in the first step, the measurement model is tested and in the second step, the structural model.

\section{Results}

Table 1 shows the means, standard deviations, alpha coefficients and the intercorrelations among all variables.

\subsection{Measurement Model}

We conducted a confirmatory factor analysis (CFA) to investigate our measurement model (see the "Appendix" for the factor loadings). To reduce the number of indicators and improve the normal distribution of the endogenous variables, the items of the Flourishing Scale were parcelled. Although this procedure is not without its critics (e.g., Marsh et al. 2013), parcelling is an approved technique to correct for measurement error, while reducing the number of indicators and improving the distribution of variables and the fit of a model (e.g., Coffman and MacCallum 2005; Little et al. 2013). Using single factor analysis, parcels were formed by first pairing the items with the highest and lowest loadings and this procedure was continued until all items were paired (Landis et al. 2000). This method performs well when the unidimensionality of the items is defensible (Rogers and Schmitt 2004). We followed the recommendation that a latent variable has at least three indicators (Kline 2011, which implies that at least 6 items are required. Therefore parcelling was only applied to the Flourishing Scale. Given the number of items and the well-documented psychometric qualities of the Flourishing Scale (Diener et al. 2010) parcelling with this method is regarded as appropriate. To form parcels, the factor loadings were determined with the use of CFA. One item of the Flourishing Scale, related to optimism, had a low factor loading. However, this 8-item scale has been extensively validated across different populations (e.g., Sumi 2014; Villieux et al. 2016). Therefore, we decided to keep the item. With the 8 items four parcels were composed.

First to investigate our measurement model, we tested a six-factor model (i.e., Map, Mav, Pap, Pav goal orientation, job insecurity, and flourishing), wherein the scales of job insecurity were combined into one factor, resulting in six latent factors, wherein the factors were allowed to covary. The goodness of fit was poor $\left(\chi^{2}(d f=362)=876.43, p<.001\right.$, $\mathrm{TLI}=.82, \mathrm{CFI}=.84, \mathrm{SRMR}=.08$, and $\mathrm{RMSEA}=.07$ (90\% CI [.07 .08]).

Subsequently, a seven-factor model was tested, with a latent factor for each scale (i.e., Map, Mav, Pap, and Pav goal orientation, quantitative and qualitative job insecurity, and 


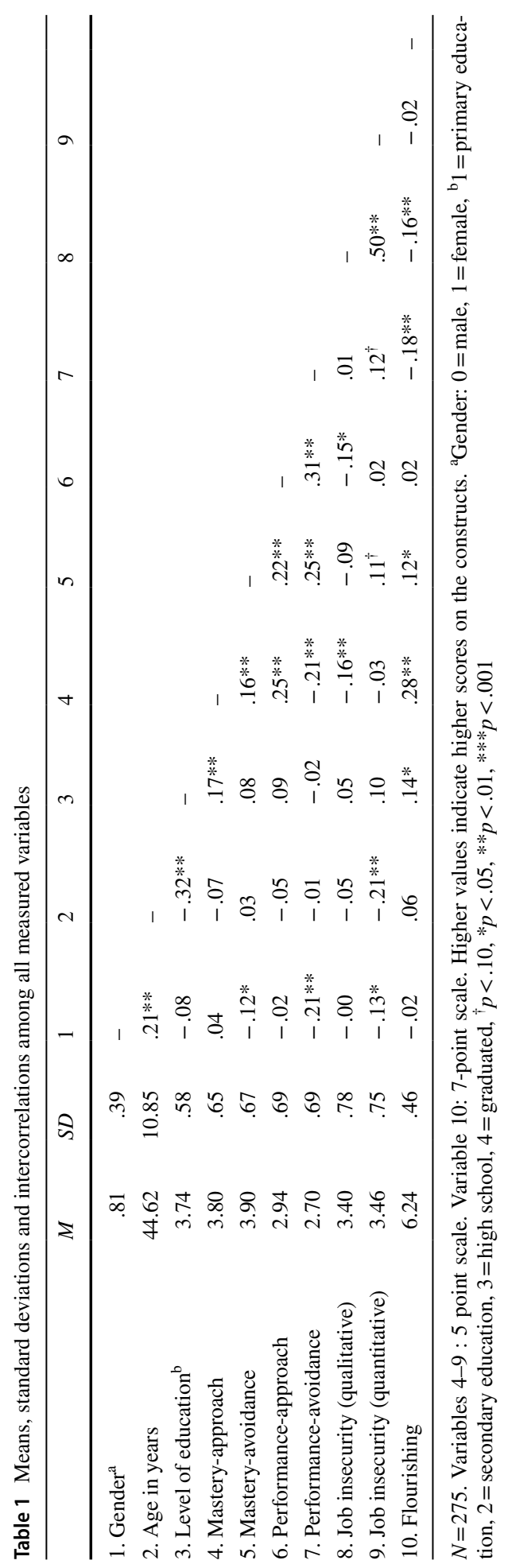


flourishing), in which the factors were allowed to covary. The goodness of fit was acceptable $\left(\chi^{2}(d f=356)=700.28, p<.001, \mathrm{TLI}=.88, \mathrm{CFI}=.89, \mathrm{SRMR}=.07\right.$, and RMSEA $=.06$ (90\% CI $[.05, .07])$. The Chi square difference test was significant $\left(\Delta \chi^{2}=176.16, \Delta d f=6\right.$, $p<.001$ ), showing that the seven-factor model had better fit with the data compared to the six-factor model. After inspection of factor loadings one item of the Qualitative job insecurity scale ("I believe that this organization will need my competence also in the future") was removed due to a low factor loadings. Furthermore, inspection of the modification indices suggested to allow the error variance of two items of the quantitative job insecurity scale to covary. The modified measurement model showed adequate fit, $\chi^{2}(328)=565.96$, $p<.001, \mathrm{TLI}=.91, \mathrm{CFI}=.92, \mathrm{SRMR}=.07$ and RMSEA $=.05(90 \% \mathrm{CI}[.04, .06])$. Therefore, this model was used to test the structural model.

\subsection{Model Testing}

To test the hypothesized model, different models were specified. For clarity, in all models Mav and Pap goal orientation were incorporated. In Model 1 (full model) all parameters were freed, which meant that the effects of Map, Mav, Pap, and Pav goal orientation on quantitative and qualitative job insecurity and flourishing were included. Model 2 only contained the hypothesized direct effects of Map and Pav goal orientation on flourishing and the indirect effects for Map and Pav goal orientation through quantitative and qualitative job insecurity on flourishing, which allowed us to detect any potential mediation effect of quantitative and qualitative job insecurity in the relation between Map and Pav goal orientation on the one hand and flourishing on the other. At last, we specified a model in which the non-significant paths (based on the results of the full model) were fixed to zero. More specifically, the following paths were fixed to zero: Pap goal orientation to flourishing, Map, Mav, Pap and Pav goal orientation to quantitative job insecurity and Mav and Pav to qualitative job insecurity. The results of the different models are presented in Table 2.

Based on the Chi squares Model 1 and the measurement model have the best fit compared to the other models (see Table 2). Model 2 had to be rejected because of the significantly higher Chi square. However, the Chi square difference between Model 1 and Model 3 was not significant $\left(\Delta \chi^{2}=7.35, \Delta d f=7, p=.39\right)$, indicating that both models fit the data equally well, which was also confirmed by the other fit indices (e.g. TLI, CFI). The Chi square index is also known to be sensitive to sample size and high correlations between variables, such as quantitative and qualitative job insecurity in our study (Kline 2011). Therefore, we compared which model fitted better with additional measures of fit: the Akaike information criterion (AIC) and the Bayesian information criterion (BIC). Both the AIC and BIC of Model 3 were lower than the other models, indicating that Model 3 had a better fit. Moreover, Model 3 is more parsimonious and therefore more preferable (Wang and Wang 2012). We, therefore, choose Model 3 as model that best fitted our data; the results of Model 3 are displayed in Fig. 2. It should be noted that AIC and BIC only ranks models, when all models are bad, they only rank from worst to even worse. The explained variance of the model $\left(R^{2}\right)$ is a better indicator of the quality of the model (Anderson 2008). The $R^{2}$ of flourishing in the two models were comparable $\left(R_{\text {Full model }}^{2}=.19 ; R_{\text {Model } 3}^{2}=.18\right)$, indicating that both did explain variance equally well and that the quality of Model 3 is at least sufficient.

Inspection of the correlation matrix and the path coefficients revealed a mild suppression effect for qualitative and quantitative job insecurity and flourishing. Quantitative job insecurity was weakly and not significantly correlated with flourishing, while in Model 3 it 


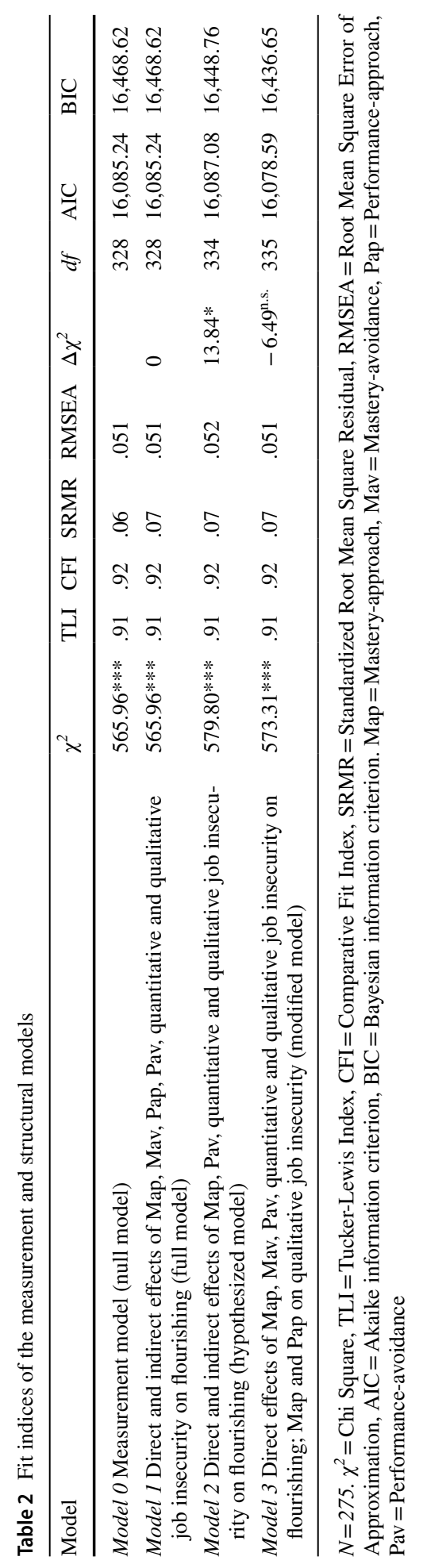




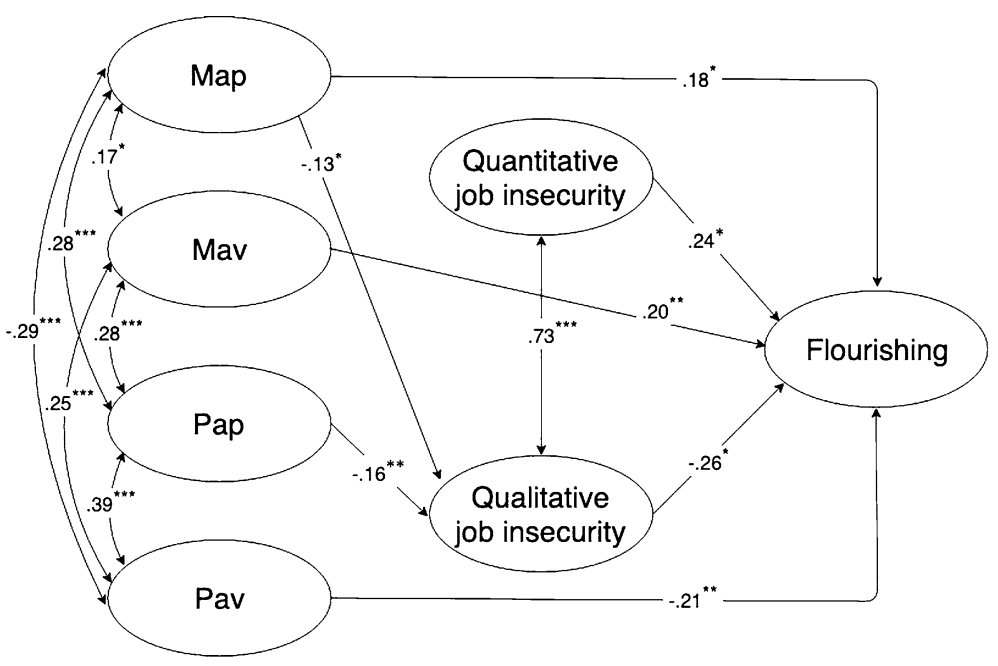

Fig. 2 Structural model with path coefficients. Note: Map=Mastery-approach, Mav=Mastery-avoidance, $\mathrm{Pap}=$ Performance-approach, Pav $=$ Performance-avoidance. The path coefficients are standardized. $\dagger p<.10, * p<.05, * * p<.001, * * * p<.001$. For the sake of clarity only (marginally) coefficients are depicted, and items serving as indicator for latent variables and error variances of the latent variables are omitted

significantly predicted flourishing. Moreover, unexpectedly quantitative job insecurity was positively related to flourishing.

The expectation that achievement goal orientation predicts flourishing was confirmed; both Map and Pav goal orientation predicted flourishing significantly (Map: $\beta=.18$, $p=.02$; Pav: $\beta=-.21, p=.01$ ). In addition, although unexpected, a Mav goal orientation positively predicted flourishing $(\beta=.20, p=.01)$, while a Pap goal orientation was not signficant. Flourishing was positively predicted $(\beta=.24, p=.05)$ by quantitative job insecurity, and negatively predicted $(\beta=-.26, p=.03)$ by qualitative job insecurity.

Our expectation that Map and Pav goal orientation predicted job insecurity (quantitative and qualitative), was only partly confirmed. None of the AGOs predicted quantitative job insecurity. It is worth noting that the correlation matrix shows that Mav and Pav goal orientation were positively correlated, although small and marginally significantly, with quantitative job insecurity (Mav: $r=.11, p<.10$; Pav: $r=.12, p<.10$ ), while Map and Pap goal orientation correlated significantly negatively with qualitative job insecurity (Map: $r=-.16, p<.01$; Pap: $r=-.15, p<.01)$. As expected, Map goal orientation negatively predicted qualitative job insecurity, while unexpectedly Pap goal orientation was also negative related.

To test any indirect effects of Map and Pav goal orientation on flourishing through quantitative and qualitative job insecurity, asymmetric confidence limits, based on the distribution of the product, and bootstrap estimation are most suitable (MacKinnon et al. 2007). Of the hypothesized effects, only a Map goal orientation was marginally significantly negatively related to qualitative job insecurity. The indirect effect of Map on flourishing, through qualitative job insecurity, was estimated with ML and subsequently bootstrapped (2000 samples) with the Bollen-Stine method (Bollen and Stine 1992) and proved to be non-significant, $b=.03,95 \% \mathrm{CI}[-.01, .10]$. This result implied that a mediation effect of Map and Pav goal orientation through job insecurity was not confirmed. 


\section{Discussion}

The present research replicates and extends past research on the relation between achievement goal orientation (AGO), flourishing and job insecurity (both quantitative and qualitative) in different ways. As far as we know this is the first study in an organizational setting that incorporated eudaimonic well-being (i.e., flourishing), and related it to AGO and job insecurity. In line with our expectations a Map goal orientation positively predicted flourishing, even when employees' jobs were threatened. On the other hand, a Pav goal orientation negatively predicted flourishing. Surprisingly, we also found a positive relationship between a Mav goal orientation and flourishing, which contradicts the negative relationship found in previous research (e.g., Elliot and McGregor 2001). An explanation for this finding might be that the relation between Mav goal orientation and well-being can be moderated by achievement domains. Most earlier studies have studied a Mav goal orientation in an educational setting. However, the strength of effects of the different AGOs seem to differ per domain (Van Yperen et al. 2014). For instance, the focus of a Mav goal orientation implies that one's competencies are up to par and will not deteriorate. Such a goal orientation could be adaptive in an environment that is primarily focused on utilizing, rather than developing, competencies. However, this orientation seems less adaptive in an educational setting, where the focus will be on further developing one's competencies. Next to this notion, the effect of Mav goal orientation could be dependent on age. Maintenance and loss-prevention goals, which are similar to Mav goals, are more common in late adulthood, but they also might promote more positive outcomes in this life phase (Ebner et al. 2006, Freund 2006). Positive effects (e.g., task interest and persistence) of a Mav goal orientation have indeed been reported especially among adults (Senko and Freund 2015). Typically, age is higher in an organizational setting than in an educational setting. Additional research on the relation between Mav goal orientation and a broad perspective on well-being (i.e. flourishing) and the moderating effects of age and domain therefore is needed.

In addition to the effects of AGO on flourishing, in line with Hellgren et al. (1999) we found that qualitative job insecurity was negatively related to flourishing, indicating the importance of qualitative job security for optimal psychological functioning. The impact of qualitative job insecurity on flourishing is further underlined by our finding that quantitative job insecurity was positively related to flourishing and acted as a suppressor variable for the predictive value of qualitative job insecurity on flourishing. Our finding is surprising considering numerous studies which show that quantitative job insecurity has significantly negative associations with well-being (e.g., Sverke et al. 2002). Anecdotal examples are well-known about people who are forced to leave an organization feeling a relief and/or a boost to make a postponed career change. Apparently the relationship between quantitative job insecurity and flourishing is more ambiguous than the relationship between job insecurity and hedonic well-being. This ambiguity is reflected in earlier studies which found no or a negative relationship between flourishing and quantitative job insecurity (Rautenbach and Rothmann 2017; Rothmann 2013). All the same, the importance of qualitative job insecurity for flourishing is clearly supported by the present study. Qualitative job insecurity, showed to be significantly negatively related to flourishing. Therefore, not only quantitative but also qualitative job insecurity should be taken in consideration when the relation with flourishing is researched. Earlier research has shown that the effects of qualitative and quantitative job insecurity on well-being are similar to each other (e.g., De Witte et al. 2010). However, our results clearly show that qualitative job insecurity is more harmful to well-being 
than quantitative job insecurity. Yet, future research needs to focus on the relationship between qualitative job insecurity and flourishing (i.e., eudaimonic well-being) to reaffirm our findings.

Our expectation that Map and Pav goal orientation were related to the appraisal of quantitative and qualitative job insecurity, was only confirmed for a Map goal orientation and qualitative job insecurity. Unexpectedly, a Pap goal orientation also proved to be negatively related to qualitative job insecurity. However, the relations were weak and the weakest in the model. A possible explanation for the weak relations between AGO and qualitative job insecurity is that our study used a cross-sectional design. Lazarus and Folkman (1987) pointed out that to examine appraisal processes persons need to be viewed over time. Considering the weak effects of Map and Pap goal orientation on qualitative job insecurity and the finding that Pav goal orientation had no effect on qualitative job insecurity, a longitudinal design with analysis on the individual level (e.g., a diary study) might reveal stronger effects of AGO on the appraisal of job insecurity. Considering the relatively weak effects of Map and Pap goal orientation on qualitative job insecurity and the finding that Pav goal orientation had no effect on qualitative job insecurity, a longitudinal design with analysis on the individual level (e.g., a diary study) might reveal stronger effects of AGO on the appraisal of job insecurity. Moreover, it is known that state goal orientations are stronger related to outcome variables such as job performance, than are dispositional goal orientations (Latham et al. 2016). For example, a diary study in which state goal orientation and perception of job insecurity are assessed, might reveal stronger associations. Especially when these are related to potentially threatful events (e.g., a message from management with information about organizational downsizing).

A possible explanation for the absence of a relation between AGO and quantitative job insecurity is that due to massive budget cuts in this population potential job loss was a reality (it was announced that nearly $30 \%$ of all employees would be dismissed). Therefore, the potential loss of their job (i.e. "I'm afraid I will lose my job") was substantial. This notion is supported by the comparison of quantitative job insecurity between our sample and a sample of Dutch employees from both private and public organizations (Vander Elst et al. 2014a, b). An independent-samples $t$ test was conducted to compare the quantitative job insecurity in the two samples. There was a significant difference between the mean of quantitative job insecurity in our study $(M=3.46, S D=.91)$ and the sample used by Vander Elst et al. $(M=2.47, S D=.75), t(667)=14.86, p<.01$. These results suggest that the sample in our study experienced a substantial amount of quantitative job insecurity. It might be possible that in an environment with a substantial threat to one's job, quantitative job insecurity is more an objective than subjective experience and therefore, less susceptible to factors that might influence this subjective experience, such as individual differences in AGO. Johns (2006) points out that context can impact organizational behaviour. Referring to Mischel (1968), Johns (2006) states that in a strong situation there is little autonomy and behaviour is constrained, thereby reducing the impact of individual differences. In a context of a substantial threat of job loss, we might expect that the autonomy of the employees with regard to quantitative job insecurity is low. This lower autonomy might obscure the relation of quantitative job insecurity with AGO. With respect to qualitative job insecurity, it is expected that employees experience more autonomy; for example, the behaviour to make a job more interesting is less restricted. This might explain that AGO is related to qualitative but not to quantitative job insecurity.

Although we found that AGO weakly influenced the appraisal of job insecurity, Map, Mav and Pav goal orientation were clearly related to flourishing. Hence, the experience of job insecurity seems not different for AGO, a mastery goal orientation (approach and 
avoidance) contributes to flourishing, even in an environment with a substantial threat of job loss.

\section{Limitations}

When interpreting the results from the present study some limitations should be considered. An import limitation is the reliance on self-report measures and associated concerns regarding common method variance. However, AGO and job insecurity constructs are subjective in nature and not easily objectified. Presumably this is also the reason why research aimed at these constructs heavily relies upon self-reports. Thereby, the scales used in this study are well validated and can rely on extensive empirical evidence (e.g. Diener et al. 2010; Vander Elst et al. 2014a, b; Van Yperen et al. 2014).

Another limitation is that our sample consisted of employees who were interested in career advice. This interest could be linked to turnover intention, which is positively associated with job insecurity (see Sverke et al. 2002). We cannot determine to what extent our findings apply to employees who were not willing, for whatever reason, to get career advice. However, the willingness to get an advice can been seen as a sign of proactively coping (i.e., seeking help) given the threat of losing one's job. Therefore, we can tentatively conclude that for employees who experience job insecurity but actively cope with this situation, the detrimental effect of job insecurity on well-being diminishes, as reported else in literature (see Klehe et al. 2012). This weakened negative effect on well-being appears to occur in our study, especially for employees with a high Map goal orientation and a low Pav goal orientation.

Another important limitation is that the study had a cross-sectional design. Any dynamics in the nature of appraisal of for instance job insecurity can only be captured with a longitudinal design, in which intra-individual differences are measured on multiple points in time. Causal inferences cannot be drawn with a cross-sectional design. However, there is theoretical and empirical evidence that dispositional variables, like AGO, influence appraisal (Lazarus and Folkman 1987) and well-being (Dweck 1986) at a certain moment in time. Another, aforementioned, limitation might be that possible effects of AGO on the appraisal of job insecurity are obscured in a 'strong' situation. The threat of losing one's job was substantial in the organization, so that for the employees of the organization job insecurity was more an objective fact than a subjective appraisal.

\section{Practical Implications}

While a mastery goal orientation is related to flourishing, it might be useful to stimulate and promote this goal orientation within employees. More specifically, a Map goal orientation can be promoted by training (Noordzij et al. 2013) and certain interventions could influence the psychological mastery climate within organizations (e.g., Dragoni 2005). Moreover, in times of downsizing, organizations can hardly influence quantitative job insecurity, yet to diminish the negative effects of job insecurity on flourishing, organizations could focus on reducing qualitative job insecurity. This can be achieved in two different ways. First, by enhancing job crafting for employees who most likely will stay in the organization, but whose jobs will change. Job crafting provides a framework to strengthen valuable aspects of a job, thereby positively influencing well-being (Tims 
et al. 2013). Secondly, by promoting career adaptability, so that employees even when they lose their jobs are better able to find qualitative good jobs (Klehe et al. 2012). To conclude, although job insecurity is becoming more inevitable and hampers well-being, AGO provides a promising avenue to counter these negative effects.

Open Access This article is licensed under a Creative Commons Attribution 4.0 International License, which permits use, sharing, adaptation, distribution and reproduction in any medium or format, as long as you give appropriate credit to the original author(s) and the source, provide a link to the Creative Commons licence, and indicate if changes were made. The images or other third party material in this article are included in the article's Creative Commons licence, unless indicated otherwise in a credit line to the material. If material is not included in the article's Creative Commons licence and your intended use is not permitted by statutory regulation or exceeds the permitted use, you will need to obtain permission directly from the copyright holder. To view a copy of this licence, visit http://creativecommons.org/licenses/by/4.0/.

\section{Appendix: Confirmatory Factor Analysis Results for Measurement Model}

Factor loadings (standardized)

Mastery approach

I am willing to select a challenging work assignment that I can learn a lot from 0.76

$\begin{array}{ll}\text { I often look for opportunities to develop new skills and knowledge } & 0.73\end{array}$

$\begin{array}{ll}\text { I enjoy challenging and difficult tasks at work where I'll learn new skills } & 0.87\end{array}$

$\begin{array}{ll}\text { For me, at work development of my ability is important enough to take risks } & 0.69\end{array}$

$\begin{array}{ll}\text { I am willing to select a challenging task that I can learn a lot from } & 0.78\end{array}$

Mastery avoidance

My goal is to avoid being incompetent at performing the skills and tasks necessary for my job 0.66

$\begin{array}{ll}\text { I hope I am able to maintain enough skills so I am competent at my job } & 0.76\end{array}$

At work, I am just trying to avoid performing the tasks required for my job poorly 0.81

At work, I focus on not doing worse than I have personally done in the past on my job 0.56

Performance approach

I'm concerned with showing that I can perform better than my co-workers $\quad 0.61$

$\begin{array}{ll}\text { I try to figure out what it takes to prove my ability to others at work } & 0.71\end{array}$

$\begin{array}{lr}\text { I enjoy it when others at work are aware of how well I am doing } & 0.69\end{array}$

$\begin{array}{lr}\text { I prefer to work on projects where I can prove my ability to others } & 0.65\end{array}$

Performance avoidance

I would avoid taking on a new task if there was a chance that I would appear rather incompetent to 0.56 others

Avoiding a show of low ability is more important to me than learning a new skill

I'm concerned about taking on a task at work if my performance would reveal that I had low ability 0.86

$\begin{array}{lr}\text { I prefer to avoid situations at work where I might perform poorly } & 0.72\end{array}$

Qualitative job insecurity

$\begin{array}{ll}\text { My future career opportunities in this organization are favourable } & 0.88\end{array}$

I feel that this organization can provide me with a stimulating job content in the near future $\quad 0.83$

$\begin{array}{ll}\text { My pay development in this organization is promising } & 0.61\end{array}$

Quantitative job insecurity

$\begin{array}{lr}\text { I'm afraid I will get fired } & 0.57\end{array}$

\begin{tabular}{ll} 
I think I will be able to stay working at this organization & 0.82 \\
\hline
\end{tabular} 
Factor loadings (standardized)

I feel insecure about the future of my job

I am sure I can keep my job

Chances are I will lose my job in two years

Flourishing ${ }^{\mathrm{a}}$

Parcel 1 (items 1 and 5)

Parcel 2 (items 3 and 8)

Parcel 3 (items 4 and 6)

Parcel 4 (items 2 and 7)

${ }^{a}$ Flourshing (item 1 = I lead a purposeful and meaningful life, $2=$ my social relationships are supportive and rewarding, $3=\mathrm{I}$ am engaged and interested in my daily activities, $4=\mathrm{I}$ actively contribute to the happiness and well-being of others, $5=\mathrm{I}$ am competent and capable in the activities that are important to me, $6=\mathrm{I}$ am a good person and live a good life, $7=\mathrm{I}$ am optimistic about my future, $8=$ people respect me)

\section{References}

Adie, J. W., Duda, J. L., \& Ntoumanis, N. (2008). Achievement goals, competition appraisals, and the psychological and emotional welfare of sport participants. Journal of Sport and Exercise Psychology, 30(3), 302-322. https://doi.org/10.1123/jsep.30.3.302.

Adie, J. W., Duda, J. L., \& Ntoumanis, N. (2010). Achievement goals, competition appraisals, and the well-and ill-being of elite youth soccer players over two competitive seasons. Journal of Sport and Exercise Psychology, 32(4), 555-579. https://doi.org/10.1123/jsep.32.4.555.

Anderson, D. R. (2008). Model based inference in the life sciences: A primer on evidence. New York: Springer.

Argyle, M. (1999). Causes and correlates of happiness. In D. Kahneman, E. Diener, \& N. Schwarz (Eds.), Well-being: Foundations of hedonic psychology (pp. 353-373). New York: Russell Sage Foundation.

AZW. (2017). Information retrieved from the database on the website Onderzoeksprogramma Arbeidsmarkt Zorg en Welzijn [Research Program Labor Market for Care and Welfare]. Retrieved December 5, 2017 from https://azwinfo.databank.nl.

Baranik, L. E., Lau, A. R., Stanley, L. J., Barron, K. E., \& Lance, C. E. (2013). Achievement goals in organizations: Is there support for mastery-avoidance? Journal of Managerial Issues, 25(1), 46-61.

Bollen, K., \& Stine, R. (1992). Bootstrapping goodness of fit measures in structural equation models. Sociological Methods and Research, 21, 205-229. https://doi.org/10.1177/0049124192021002004.

Briscoe, J. P., Hall, D. T., \& Frautschy DeMuth, R. L. (2006). Protean and boundaryless careers: An empirical exploration. Journal of Vocational Behavior, 69(1), 30-47. https://doi.org/10.1016/j. jvb.2005.09.003.

Cheng, G. H. L., \& Chan, D. K. S. (2008). Who suffers more from job insecurity? A meta-analytic review. Applied Psychology, 57, 272-303. https://doi.org/10.1111/j.1464-0597.2007.00312.x.

Coffman, D. L., \& MacCallum, R. C. (2005). Using parcels to convert path analysis models into latent variable models. Multivariate Behavioral Research, 40(2), 235-259.

De Witte, H. (2005). Job insecurity: Review of the international literature on definitions, prevalence, antecedents and consequences. SA Journal of Industrial Psychology, 31(4), 1-6. https://doi.org/10.4102/ sajip.v31i4.200.

De Witte, H. (2010). Job insecurity and psychological well-being: Review of the literature and exploration of some unresolved issues. European Journal of Work and Organizational Psychology, 8, 155-177. https://doi.org/10.1080/135943299398302.

De Witte, H., De Cuyper, N., Handaja, Y., Sverke, M., Näswall, K., \& Hellgren, J. (2010). Associations between quantitative and qualitative job insecurity and well-being. International Studies of Management and Organization, 40(1), 40-56. https://doi.org/10.2753/imo0020-8825400103. 
De Witte, H., Pienaar, J., \& De Cuyper, N. (2016). Review of 30 years of longitudinal studies on the association between job insecurity and health and well-being: Is there causal evidence? Australian Psychologist, 51, 18-31. https://doi.org/10.1111/ap.12176.

Deci, E. L., \& Ryan, R. M. (2000). The "what" and "why" of goal pursuits: Human needs and the selfdetermination of behavior. Psychological Inquiry, 11, 227-268. https://doi.org/10.1207/S15327965P LI1104_01.

Deci, E. L., \& Ryan, R. M. (2008). Hedonia, eudaimonia, and well-being: An introduction. Journal of Happiness Studies, 9(1), 1-11. https://doi.org/10.1007/s10902-006-9018-1.

Diener, E., Wirtz, D., Tov, W., Kim-Prieto, C., Choi, D. W., Oishi, S., et al. (2010). New well-being measures: Short scales to assess flourishing and positive and negative feelings. Social Indicators Research, 97, 143-156. https://doi.org/10.1007/s11205-009-9493-y.

Dragoni, L. (2005). Understanding the emergence of state goal orientation in organizational work groups: The role of leadership and multilevel climate perceptions. Journal of Applied Psychology, 90, 10841095. https://doi.org/10.1037/0021-9010.90.6.1084.

Dweck, C. S. (1986). Motivational processes affecting learning. American Psychologist, 41, 1040-1048. https://doi.org/10.1037/0003-066x.41.10.1040.

Dweck, C. S., \& Leggett, E. L. (1988). A social cognitive approach to motivation and personality. Psychological Review, 9, 256-273. https://doi.org/10.1037//0033-295X.95.2.256.

Dykman, B. M. (1998). Integrating cognitive and motivational factors in depression: Initial tests of a goalorientation approach. Journal of Personality and Social Psychology, 74 (1), 139-158.

Ebner, N. C., Freund, A. M., \& Baltes, P. B. (2006). Developmental changes in personal goal orientation from young to late adulthood: From striving for gains to maintenance and prevention of losses. Psychology and Aging, 21, 664-678. https://doi.org/10.1037/0882-7974.21.4.664.

Elliot, A. J., \& McGregor, H. A. (2001). A $2 \times 2$ achievement goal framework. Journal of Personality and Social Psychology, 80, 501-519. https://doi.org/10.1037/0022-3514.80.3.501.

Elliot, A. J., \& Reis, H. T. (2003). Attachment and exploration in adulthood. Journal of Personality and Social Psychology, 85(2), 317-331. https://doi.org/10.1037/0022-3514.85.2.317.

Elliot, A. J., Sheldon, K. M., \& Church, M. A. (1997). Avoidance personal goals and subjective wellbeing. Personality and Social Psychology Bulletin, 23(9), 915-927. https://doi.org/10.1177/01461 67297239001.

Elliot, A. J., Thrash, T. M., \& Murayama, K. (2011). A longitudinal analysis of self-regulation and wellbeing: Avoidance personal goals, avoidance coping, stress generation, and subjective well-being. Journal of Personality, 79, 643-674. https://doi.org/10.1111/j.1467-6494.2011.00694.x.

Emmons, R. A. (2003). Personal goals, life meaning, and virtue. In C. L. M. Keyes \& J. Haidt (Eds.), Wellsprings of a positive life. Flourishing: Positive psychology and the life well-lived (pp. 105128). Washington, DC: American Psychological Association.

Eurofound. (2016). Sixth European working conditions survey-Overview report. Luxembourg: Publications Office of the European Union.

Fredrickson, B. L., Grewen, K. M., Coffey, K. A., Algoe, S. B., Firestine, A. M., Arevalo, J. M., et al. (2013). A functional genomic perspective on human well-being. Proceedings of the National Academy of Sciences, 110, 13684-13689. https://doi.org/10.1073/pnas.1305419110.

Freund, A. M. (2006). Differential motivational consequences of goal focus in younger and older adults. Psychology and Aging, 21, 240-252. https://doi.org/10.1037/0882-7974.21.2.240.

Greenhalgh, L., \& Rosenblatt, Z. (1984). Job insecurity: Toward conceptual clarity. Academy of Management Review, 9(3), 438-448. https://doi.org/10.5465/amr.1984.4279673.

Griep, Y., Kinnunen, U., Nätti, J., De Cuyper, N., Mauno, S., Mäkikangas, A., et al. (2016). The effects of unemployment and perceived job insecurity: A comparison of their association with psychological and somatic complaints, self-rated health and life satisfaction. International Archives of Occupational and Environmental Health, 89, 147-162. https://doi.org/10.1007/s00420-015-1059-5.

Hallquist, M. N., \& Wiley, J. F. (2018). MplusAutomation: An R package for facilitating large-scale latent variable analyses in Mplus. Structural Equation Modeling. https://doi.org/10.1080/10705 511.2017.1402334.

Handaja, Y., \& De Witte, H. (2007). Kwantitatieve en kwalitatieve baanonzekerheid: Samenhangen met arbeidstevredenheid en psychisch welzijn [Quantitative and qualitative job insecurity: Relations with job satisfaction and well-being]. Gedrag en Organisatie, 20, 137-159.

Hellgren, J., Sverke, M., \& Isaksson, K. (1999). A two-dimensional approach to job insecurity: Consequences for employee attitudes and well-being. European Journal of Work and Organizational Psychology, 8, 179-195. https://doi.org/10.1080/135943299398311.

Hoyle, R. H. (Ed.). (2012). Handbook of structural equation modeling. New York: Guilford Press. 
Hu, L. T., \& Bentler, P. M. (1999). Cutoff criteria for fit indexes in covariance structure analysis: Conventional criteria versus new alternatives. Structural Equation Modeling, 6, 1-55. https://doi. org/10.1080/10705519909540118.

Huang, C. (2011). Achievement goals and achievement emotions: A meta-analysis. Educational Psychology Review, 23(3), 359-388. https://doi.org/10.1007/s10648-011-9155-X.

Johns, G. (2006). The essential impact of context on organizational behavior. Academy of Management Review, 31(2), 386-408. https://doi.org/10.5465/amr.2006.20208687.

Kaplan, A., \& Maehr, M. L. (1999). Achievement goals and student well-being. Contemporary Educational Psychology, 24, 330-358. https://doi.org/10.1006/ceps.1999.0993.

Keyes, C. L. (2002). The mental health continuum: From languishing to flourishing in life. Journal of Health and Social Behavior. https://doi.org/10.2307/3090197.

Keyes, C. L. (2007). Promoting and protecting mental health as flourishing: A complementary strategy for improving national mental health. American Psychologist, 62(2), 95-108. https://doi. org/10.1037/0003-066x.62.2.95.

Klehe, U. C., Zikic, J., van Vianen, A. E., Koen, J., \& Buyken, M. (2012). Coping proactively with economic stress: Career adaptability in the face of job insecurity, job loss, unemployment, and underemployment. The role of the economic crisis on occupational stress and well being. In P. L. Perrewé, J. R. B. Halbesleben, \& C. C. Rose (Eds.), Research in occupational stress and well-being: volume 10. The role of the economic crisis on occupational stress and well being (pp. 131-176). Bingley: Emerald Group Publishing. https://doi.org/10.1108/s1479-3555(2012)0000010008.

Kline, R. (2011). Principles and practice of structural equation modeling. Methodology in the social sciences (3rd ed.). New York: Guilford Press.

Landis, R. S., Beal, D. J., \& Tesluk, P. E. (2000). A comparison of approaches to forming composite measures in structural equation models. Organizational Research Methods, 3, 186-207. https://doi. org/10.1177/109442810032003.

Latham, G., Seijts, G., \& Slocum, J. (2016). The goal setting and goal orientation labyrinth. Organizational Dynamics, 45(4), 271-277. https://doi.org/10.1016/j.orgdyn.2016.10.001.

Lazarus, R. S., Deese, J., \& Osler, S. F. (1952). The effects of psychological stress upon performance. Psychological Bulletin, 49, 293-317. https://doi.org/10.1037/h0061145.

Lazarus, R. S., \& Folkman, S. (1987). Transactional theory and research on emotions and coping. European Journal of Personality, 1, 141-169. https://doi.org/10.1002/per.2410010304.

Leka, S., \& Jain, A. (2010). Health impact of psychosocial hazards at work: An overview. Geneva: World Health Organization.

Lim, V. K., \& Sng, Q. S. (2006). Does parental job insecurity matter? Money anxiety, money motives, and work motivation. Journal of Applied Psychology, 91, 1078-1087. https://doi. org/10.1037/0021-9010.91.5.1078.

Lin, Y. (2015). Are you a protean talent? The influence of protean career attitude, learning-goal orientation and perceived internal and external employability. Career Development International, 20(7), 753-772. https://doi.org/10.1108/cdi-04-2015-0056.

Little, T. D., Rhemtulla, M., Gibson, K., \& Schoemann, A. M. (2013). Why the items versus parcels controversy needn't be one. Psychological Methods, 18, 285-300. https://doi.org/10.1037/a0033266.

MacKinnon, D. P., Fairchild, A. J., \& Fritz, M. S. (2007). Mediation analysis. Annual Review of Psychology, 58, 593-614. https://doi.org/10.1146/annurev.psych.58.110405.085542.

Marsh, H. W., Lüdtke, O., Nagengast, B., Morin, A. J., \& Von Davier, M. (2013). Why item parcels are (almost) never appropriate: Two wrongs do not make a right-camouflaging misspecification with item parcels in CFA models. Psychological Methods, 18, 257-284.

Mischel, W. (1968). Personality and assessment. New York: Wiley. https://doi.org/10.1177/0013164468 02800341 .

Näswall, K., \& De Witte, H. (2003). Who feels insecure in Europe? Predicting job insecurity from background variables. Economic and Industrial Democracy, 24, 189-215. https://doi.org/10.1177/01438 $31 \mathrm{X} 03024002003$.

Noordzij, G., Van Hooft, E. A., Mierlo, H., van Dam, A., \& Born, M. P. (2013). The effects of a learning goal orientation training on self-regulation: A field experiment among unemployed job seekers. Personnel Psychology, 66, 723-755. https://doi.org/10.1111/peps.12011.

Organisation for Economic Co-operation and Development. (1997). OECD employment outlook 1997. Paris: OECD Publishing. https://doi.org/10.1787/empl_outlook-1997-en.

Payne, S. C., Youngcourt, S. S., \& Beaubien, J. M. (2007). A meta-analytic examination of the goal orientation nomological net. Journal of Applied Psychology, 92, 128-150. https://doi. org/10.1037/0021-9010.92.1.128. 
R Core Team. (2012). R: A language and environment for statistical computing. R Foundation for Statistical Computing, Vienna, Austria. ISBN 3-900051-07-0. Retrieved July 5, 2019 from http://www.Rproject.org.

Rautenbach, C., \& Rothmann, S. (2017). Antecedents of flourishing at work in a fast-moving consumer goods company. Journal of Psychology in Africa, 27(3), 227-234. https://doi.org/10.1080/14330 237.2017.1321846.

Rogers, W. M., \& Schmitt, N. (2004). Parameter recovery and model fit using multidimensional composites: A comparison of four empirical parceling algorithms. Multivariate Behavioral Research, 39, 379-412. https://doi.org/10.1207/S15327906MBR3903_1.

Rothmann, S. (2013). Flourishing at work: A Southern African perspective. In M. P. Wissing (Ed.), Cross-cultural advancements in positive psychology (pp. 123-151). New York: Springer.

Ryan, R. M., \& Deci, E. L. (2001). On happiness and human potentials: A review of research on hedonic and eudaimonic well-being. Annual Review of Psychology, 52, 141-166. https://doi.org/10.1146/ annurev.psych.52.1.141.

Senko, C., \& Freund, A. M. (2015). Are mastery-avoidance achievement goals always detrimental? An adult development perspective. Motivation and Emotion, 39(4), 477-488. https://doi.org/10.1007/ s11031-015-9474-1.

Sumi, K. (2014). Reliability and validity of Japanese versions of the flourishing scale and the scale of positive and negative experience. Social Indicators Research, 118, 601-615. https://doi. org/10.1007/s11205-013-0432-6.

Sverke, M., \& Hellgren, J. (2002). The nature of job insecurity: Understanding employment uncertainty on the brink of a new millennium. Applied Psychology: An International Review, 66, 28-30. https://doi. org/10.1111/1464-0597.0077z.

Sverke, M., Hellgren, J., \& Näswall, K. (2002). No security: A meta-analysis and review of job insecurity and its consequences. Journal of Occupational Health Psychology, 7, 242-264. https://doi. org/10.1037//1076-8998.7.3.

Tims, M., Bakker, A. B., \& Derks, D. (2013). The impact of job crafting on job demands, job resources, and well-being. Journal of Occupational Health Psychology, 18, 230-240. https://doi.org/10.1037/a0032 141.

Tuominen-Soini, H., Salmela-Aro, K., \& Niemivirta, M. (2008). Achievement goal orientations and subjective well-being: A person-centred analysis. Learning and Instruction, 18, 251-266. https://doi. org/10.1016/j.learninstruc.2007.05.003.

Van Yperen, N. W., Blaga, M., \& Postmes, T. (2014). A meta-analysis of self-reported achievement goals and nonself-report performance across three achievement domains (work, sports, and education). PLoS ONE. https://doi.org/10.1371/journal.pone.0093594.

Vander Elst, T., De Witte, H., \& De Cuyper, N. (2014a). The job insecurity scale: A psychometric evaluation across five European countries. European Journal of Work and Organizational Psychology, 23, 364-380. https://doi.org/10.1080/1359432X.2012.745989.

Vander Elst, T., Richter, A., Sverke, M., Näswall, K., De Cuyper, N., \& De Witte, H. (2014b). Threat of losing valued job features: The role of perceived control in mediating the effect of qualitative job insecurity on job strain and psychological withdrawal. Work and Stress, 28, 143-167. https://doi. org/10.1080/02678373.2014.899651.

VandeWalle, D. (1997). Development and validation of a work domain goal orientation instrument. Educational and Psychological Measurement, 57, 995-1015. https://doi.org/10.1177/001316449705700 6009.

Vandewalle, D., Nerstad, C. G., \& Dysvik, A. (2019). Goal orientation: A review of the miles traveled and the miles to go. Annual Review of Organizational Psychology and Organizational Behavior, 6, 115144. https://doi.org/10.1146/annurev-orgpsych-041015-062547.

Villieux, A., Sovet, L., Jung, S. C., \& Guilbert, L. (2016). Psychological flourishing: Validation of the French version of the flourishing scale and exploration of its relationships with personality traits. Personality and Individual Differences, 88, 1-5. https://doi.org/10.1016/j.paid.2015.08.027.

Wang, J., \& Wang, X. (2012). Structural equation modeling: Applications using Mplus. Chichester, UK: Higher Education Press.

Westman, M., Etzion, D., \& Danon, E. (2001). Job insecurity and crossover of burnout in married couples. Journal of Organizational Behavior, 22, 467-481. https://doi.org/10.1002/job.91.

Publisher's Note Springer Nature remains neutral with regard to jurisdictional claims in published maps and institutional affiliations. 